\title{
HIPERTEXTUALIDAD E IMITACIÓN (A PROPÓSITO DE LOS «ESPÍRITUS DE AMOR» EN GARCILASO)
}

\author{
Armando Pego Puigbó \\ Instituto de la Lengua Española \\ CSIC-Madrid
}

\section{PARA UNA FILOLOGÍA HISTÓRICA: UNA RELACIÓN REMOTIVADA DE LOS GÉNEROS}

La práctica de la «imitación» no sólo representa la base de la producción literaria renacentista sino que, simultáneamente, ha constituido la columna vertebral del pensamiento poético que contribuyó a alumbrar y que sirvió para cincelar la literatura occidental durante al menos cinco siglos, desde Dante, Petrarca o Boccacio hasta la irrupción de nuevas perspectivas dentro de la teoría literaria neoclásica ${ }^{1}$. Nada nuevo añado tampoco con la convicción de que el concepto de «imitación» desborda las nociones lingüísticas y literarias y que, por esta misma razón, ni tan siquiera puede ser englobado exclusivamente bajo una sola doctrina filosófica o retórica, sea platónica, aristotélica o helenístico-latina ${ }^{2}$. La ya casi inabarcable bibliografía contemporánea sobre este tema, que, como siempre sucede, acaba por requerir la consulta de obras monumentales como la de Weinberg, ha insistido en un movimiento de ida y vuelta, que pone de relieve la penetración mutua entre la «poética» y la «poesía», entre los tra-

${ }^{1}$ René WELLEK, Historia de la crítica literaria moderna (1750-1950). La segunda mitad del siglo XVIII, Madrid, Gredos, 1959, p. 16. Muy recientemente acaba de salir publicado, en el ámbito español, David Viñas, Historia de la crítica literaria, Barcelona, Ariel, 2002.

2 «Esta incertitud por lo que al sentido de la imitatio respecta, este deslizamiento continuo de un significado a otro se manifiesta no sólo en los tratados generales de Poética, sino que una misma fluctuación se observará también en algunos de los tratados De imitatione» (Ángel GARCÍA GALIANO, La imitación poética en el Renacimiento, Kassel, Edition Reichenberger, 1992, p. 30).

Rlit, LXV, 129 (2003), 5-29 
tados y las obras ${ }^{3}$. No es por ello extraño que la «imitación de modelos» que guía las cuidadas anotaciones a Garcilaso de un gramático como el Brocense se trueque en la forma misma de plantear Fernando de Herrera su texto, las Anotaciones, cuya «gran originalidad reside en la concurrencia en un mismo lugar de numerosas fuentes, amalgamadas hábilmente dentro de un prosa fluida» ${ }^{4}$. Las Anotaciones de Herrera se desvían del género del «tratado de poética» para experimentar con las propias posibilidades que el sistema literario proporciona. En gran medida, la plurivalente «imitación» permite ampliar la definición de las relaciones genéricas desde las conexiones entre el asunto y su tratamiento a las relaciones entre clases literarias y clases de conocimiento ${ }^{5}$. En este sentido, los procedimientos de transformación habituales entre unos géneros literarios y otros pueden operar como ley general en otro tipo de textos y acabar atrayéndolos hacia la órbita del sistema comunicativo tal como es empleado en literatura. Por ello, se ha conjeturado como posible que Herrera advirtiese que el comentario filológico, no tanto en su vertiente más escolar ${ }^{6}$ cuanto en su capacidad explicativa, pudiese acoger el género del ensayo, como ya lo habían acogido antes la epístola o las misceláneas ${ }^{7}$.

Así, por ejemplo, sin entrar en discusiones técnicas sobre las interferencias que en la poesía de Herrera se producen entre canción y elegía, los discursos que antepuso a las anotaciones de cada uno de los géneros practicados por Garcilaso, principalmente el de los sonetos, pero también los de las elegías y églogas, funcionan tanto como un lugar de encuentro de

${ }^{3}$ B. E. WeInBerg, A History of Literary Criticism in the Italian Renaissance, Chicago, University Press, 1961.

${ }^{4}$ Bienvenido MORROS, «Las fuentes y su uso en las Anotaciones a Garcilaso», en Grupo P.A.S.O., Las «Anotaciones» de Fernando de Herrera, Sevilla, Universidad, 1997, p. 58. Para las Anotaciones del Brocense, uso la edición de Antonio GALlEGo MORELL, Garcilaso de la Vega y sus comentaristas, 2. ${ }^{a}$ edición revisada y adicionada, Madrid, Gredos, 1972. En el caso de Herrera, empleo la edición reciente de Inoria PEPE y José María ReYes, Anotaciones a la poesía de Garcilaso, Madrid, Cátedra, 2001 (entre paréntesis, añado la página de la edición de Gallego Morell).

${ }^{5}$ Rosalie L. COLIE, The Resources of Kind. Genre-Theory in the Renaissance, Berkeley, University of California, 1973, p. 29.

${ }^{6}$ Carmen Codoñer advirtió las consecuencias indeseadas que el modelo herreriano haya podido tener en un comentario literario destinado a la «caza de figuras» y «a una acumulación de erudición totalmente ajena a la labor del comentarista», en contraposición a la tarea precisa y modesta del Brocense cuyo «afán primordial es aclarar el texto en sus dos vertientes, lingüística y literaria, concebida esta última, casi exclusivamente, como análisis de la imitatio» («Comentaristas de Garcilaso», en Víctor GARCía DE LA ConchA (ed.), Academia Literaria Renacentista IV. Garcilaso, Salamanca, Universidad, 1986 , pp. 196 y 200). Una visión más positiva de la labor de Herrera puede encontrarse en su aportación al volumen colectivo citado del Grupo P.A.S.O. («El modelo filológico de las Anotaciones», pp. 17-36).

7 Jesús GómeZ (ed.), El ensayo español: siglos XV al XVII, Barcelona, Crítica, 1996, pp. $46-48$. 
diversas fuentes, cuya autoría normalmente omitida ha dado incluso pie a poner en duda la integridad intelectual de Herrera ${ }^{8}$ cuanto de un espacio textual que busca su autonomía separándose del seguimiento estrecho, gramatical, del modelo tradicional de comentario. El texto anotador «imita» de diversas fuentes, y lo hace normalmente a través de la traducción. Ello supone, al menos, una mínima transformación estilística al servicio de un macrotexto que es el que ha de garantizar el ensamblaje unitario de las diferentes partes. Aunque bajo presupuestos modernos podría tildarse de plagio el uso literal de diversos pasajes, en un ambiente que ya ha asimilado e integrado las polémicas sobre la «imitación simple» y la «imitación ecléctica», como las que se produjeron entre finales del siglo XV y principios del XVI entre Poliziano y Cortese, entre Pico y Bembo, a favor de la última, la práctica de la «imitación» estaba logrando ampliarse hacia el horizonte mismo de la «crítica» literaria.

Es, pues, el ámbito de estas Anotaciones herrerianas un lugar privilegiado de cruce entre actividades propias de la historia literaria y de aquellas que, en un sentido más amplio, cabalgan entre la crítica y la teoría de la literatura. $\mathrm{Y}$ es precisamente, también, la polisemia del termino «imitación» la que hace más rentable una perspectiva de lectura que oscila entre el comentario filológico que data los textos, anota sus fuentes y descubre posibles influencias, y la teoría literaria que tiene por objeto explicar un texto según unos principios generales, a fin de poder llegar a una comprensión cada vez más profunda de su sentido. Si, como ha afirmado Miguel Ángel Garrido, no existe solución de continuidad entre poética estética y poética lingüística $\mathrm{y}$, en un paso más allá, entre poética y retórica ${ }^{9}$, sería posible admitir que una de las tareas del análisis de textos consiste en proponer vías semánticas de acceso al sentido a partir de las posibilidades pragmáticas que la interpretación incluye desde su raíz. Es decir, se trataría de combinar los resultados que ofrece la historia literaria con la aplicación de las categorías y criterios generales de la teoría que la crítica lleva a cabo.

Desde este punto de vista, la crítica actuaría como una poética práctica, puesto que, por un lado, presupone un conjunto de herramientas lingüísticas, estéticas y hermenéuticas sólidamente establecidas y susceptibles de ser aplicadas coherentemente, y, por otro, evita el riesgo de derivas interpretativas, gratuitas o arbitrarias, al modo de una práctica poética, mediante el control que ejerce la tradición filológica del comentario, alerta ante la «acumulación de erudición» o ante los reductivismos clasificadores de una

\footnotetext{
${ }^{8}$ Fernando LÁzaro CARRETER, «Dos notas sobre la poética del soneto en los "Comentarios de Herrera"», Anales de Literatura Hispanoamericana 8 (1980): 315-321.

${ }^{9}$ Miguel Ángel GARRIDo, Nueva Introducción a la Teoría de la Literatura, Madrid, Síntesis, 2000, p. 13.
} 
retórica elocutiva (elenco de figuras) o incluso, en el siglo XX, una retórica «dispositiva» (excesos narratológicos). Esta poética práctica pudiera llegar a servir, en su momento, como un afluente metodológico de una Poética histórica aún por hacer, pero que cuenta con planteamientos sólidos en la obra de H. R. Jauss y de S. J. Schmidt, entre otros ${ }^{10}$. Más que del espacio mediador entre la historia y la teoría, como Augusto Schlegel se esforzó en caracterizar, este tipo de poética que aquí propongo constituye un lugar de confluencia de la historia y la teoría ${ }^{11}$. De este modo, la aspiración universal de la teoría se mantiene arraigada en la condición histórica de la obra literaria. La búsqueda de un sentido tantearía el sentido en su historia. Un sentido histórico, por tanto.

Habiendo partido de los primeros comentaristas de Garcilaso, he llegado a unas conclusiones hermenéuticas situadas en el arco que puede trazarse entre la razón histórica de Ortega y el horizonte de expectativas de Jauss. Pese a lo que pudiera parecer, no creo estar desviándome del propósito inicial, pues la «imitación» constituye por sí misma un magnífico ejemplo de categoría que pertenece por derecho propio a esta poética práctica. Como se ha señalado, la «imitación» clásica consistía básicamente en la imitación de modelos, que exige del comentarista, por tanto, una búsqueda de fuentes como fundamento de un tipo de investigación cultural. No se olvide, a estos efectos, que a la gramática se le encomendaba, a la vez, la tarea de la verborum interpretatio y de la poetarum enarratio. A la retórica, por su parte, sobre todo por influencia de S. Agustín, se le asignó la labor exegética de la poetarum interpretatio ${ }^{12}$. Por otra parte, en fecha tardía, a mediados del siglo XVI, gracias a la traducción de Francesco Robortello, la mímesis aristotélica es redescubierta y comienza su fecunda andadura en la discusión de las Poéticas hasta llegar a convertirse, a partir del siglo XVIII, en su piedra de toque.

Aun reconociendo que «la más honda inspiración del Renacimiento era retórica» y que «el Humanismo fue, fundamentalmente, un movimiento imitativo en su verdadera raíz y esencia» ${ }^{13}$, y aun admitiendo por razones evidentes que la imitación en Garcilaso, de algunos de cuyos poemas nos hemos de ocupar más adelante, es «imitación de modelos», no me parece ocioso, desde la perspectiva crítica actual, insistir en este hilo mimético que habría de convertirse en anchuroso caudal. Y ha de insistirse, no por

${ }^{10}$ H. R. JAUSS, «La historia literaria como desafío a la ciencia literaria», La actual ciencia literaria alemana, Salamanca, Anaya, 1971, pp. 37-114; S. J. SCHMIDT, Fundamentos de la ciencia empírica de la literatura, Madrid, Taurus, 1990.

11 René WelleK, Historia de la crítica moderna (1750-1950). El Romanticismo, Madrid, Gredos, 1962, pp. 67-70.

${ }^{12}$ C. CODOÑER, art. cit., pp. 186-188.

13 Á. García Galiano, op. cit., p. 31. 
una inclinación teórica al anacronismo, sino por dos razones fuertemente enlazadas, una de índole histórica y otra crítico-teórica. Dejando ahora a un lado el rigor filológico del Brocense, ya el propio Herrera, por más que su estética fuese platonizante, comentaba a Garcilaso reuniendo las opiniones y los juicios que se ventilaban en los debates teóricos de la época, anotados convenientemente, entre otros, por Fernando Lázaro Carreter y Bienvenido Morros. Pero los reunía también para producir su propio discurso teórico, hasta el punto de que las interferencias que mencionábamos entre la elegía y la canción no sólo responden a unos planteamientos teóricos de base determinados por la propia producción poética, hecho que ha sido explicado sagazmente por Begoña López Bueno ${ }^{14}$. Constituyen, además, una marca entre otras de la necesidad textual de superar el modelo del comentario filológico, que es el que sigue el Brocense, para acogerse al género del ensayo. Imitación de modelos, sí, como planteamiento teórico, cuya exposición, sin embargo, se rige por reglas genéricas propias, por más que en principio resulten inestables. El análisis literario parece iniciar con Herrera un conjunto de tentativas en busca de un cauce que permitiese transformar su condición dependiente de otro texto en un discurso autónomamente configurado. La productividad genérica que de ello se deriva tiende, en consecuencia, al establecimiento de una lógica interna que traba sus distintas partes de acuerdo a un marco temático-estructural común. Un marco cuya fábula o materia - la anotación de otro texto- el comentario crítico, próximo ya al ensayo, alumbra a partir de la lectura, es decir, a partir de lo que Paul Ricoeur llama la Mímesis III; una refiguración que da paso, en un movimiento dialéctico, a una nueva construcción «que mira no tanto a restituir la intención del autor detrás del texto como a explicitar el movimiento por el que el texto despliega un mundo, en cierto modo, delante de sí mismo» ${ }^{15}$.

Comprender ese momento que instaura la diferencia de las obras, y que permite, en consecuencia, la factible superación de los modelos, como tan bien comprendieron los defensores, entre ellos Herrera, de la «imitación compuesta», contribuye a crear el sentido histórico de los textos, puesto que, como estamos viendo, la interpretación de Herrera no sólo marca la comprensión posterior de Garcilaso sino que incide en el propio curso de la poesía española del siglo XVII. La inserción en la tradición cultural, en que se inspira la «imitación», vive de la traición al ejemplar, pues la presupone y ha de transformarla. Más aún en el caso de la poesía, donde, de un modo especial, se ventilan los límites de la ficción: entre la imitación de modelos y la imitación de discursos (de la Beatriz de Dante a las Cloris

14 Begoña LÓPEZ BUENO, «Las Anotaciones y los géneros poéticos», en Grupo P.A.S.O., op. cit., pp. 183-199.

${ }^{15}$ Paul Ricoeur, Tiempo y narración I, Madrid, Cristiandad, 1987, p. 158. 
que pueblan tantos poemas de los Siglos de Oro, por ejemplo), la lírica debate su estatuto enunciativo ${ }^{16}$.

La irreductibilidad, en última instancia, de los significados en tensión en la imitación contiene, no obstante, una enorme energía teórica, como he señalado más arriba. Tal irreductibilidad no debería verse como incompatibilidad ni, en una versión más suavizada, como contradicción sólo abordable colocando la imitación y la mímesis a ambos lados de una balanza, cuyo fiel bien podría ser la doctrina platónica de la copia de las Ideas. No me resisto a advertir que es posible su conflictiva intersección y a proponer algunas estrategias (parciales) para sacar rendimiento poético de esta situación. Ya se ha indicado someramente el lugar de la «imitatio» en el paradigma de la Poética clasicista. Es el momento de dar entrada a las investigaciones de Gerard Genette sobre la literatura en segundo grado. Aun procediendo del estructuralismo, Genette mantiene, si se pudiera así hablar, una relación carnal con las obras literarias. A diferencia de otros estructuralistas, no se ha detenido tanto a radiografiar cuerpos cuanto a la investigación histiológica y genómica. Ha intentado establecer la red de conexiones que garantizan el funcionamiento del organismo literario y la filiación estructural de su renovada vitalidad. Al lado de su trilogía de Figuras, me interesa en este momento el paso de Introduction à l'architexte a $\mathrm{Pa}$ limpsestes.

En el primero, trazaba un marco general de las clases de imitación, es decir, de géneros, de acuerdo con las situaciones de enunciación que establecía el sistema modal platónico-aristotélico. Hacía notar que en este esquema los géneros líricos quedaban desterrados, sin otra opción que «la anexión valorativa o la expulsión a las tinieblas exteriores, o, si se prefiere, a los limbos de la "imperfección"» ${ }^{17}$. Es cierto que Genette, pese a todo, ha podido llevar a cabo una abusiva extrapolación de la mímesis a la diégesis, incluso en un libro tan matizado como Ficción y dicción. Sin embargo, conviene retener que entre el esquematismo clásico y la abstracción de la teoría romántica, para Genette «no hay archigéneros que escapen totalmente de la historicidad y que mantengan a la vez una definición genérica» ${ }^{18}$. En Palimpsestes esta convicción le llevaba a ver la percepción genérica como el medio de orientar y determinar en gran medida el

16 Ángel Luis Luján ATIENZA, «La lírica y los límites de la ficción», Revista de Literatura 123 (2000): 5-18. Una excelente revisión crítica de las diversas teorías sobre el sujeto lírico podrá verse en el capítulo primero de su próximo libro Pragmática del discurso lírico (Teoría de la enunciación del poema), cuyo manuscrito el autor ha tenido la amabilidad de darme a leer.

17 Gerard GenetTE, Introduction à l'architexte, París, Seuil, 1981. Puede consultarse también, «Géneros, "tipos", modos», en Miguel Ángel Garrido Gallardo (ed.), Teoría de los géneros literarios, Madrid, Arco, 1988, pp, 183-233 (para la cita, p. 201).

18 Ibíd., p. 232. 
horizonte de recepción de la obra por el lector ${ }^{19}$. Ahora bien, la architextualidad no opera aisladamente sino que, por el contrario, mantiene un fluido intercambio con lo que Genette llama hipertextualidad, a saber, la relación que une a un texto con otro anterior. El teórico francés ejemplifica las vinculaciones entre estos dos tipos transtextuales con la novela picaresca española que, en cuanto género, surge en el momento que se pone en relación la obra concreta del Guzmán de Alfarache con la del Lazarillo ${ }^{20}$. En suma, la historicidad de los géneros se apoya en la capacidad de serializar las singularidades. Unos textos remiten a otros, establecen entre ellos unas relaciones de hipertextualidad y, por consiguiente, en un sentido amplio, fundan la genericidad, como quiere J. M. Schaeffer, «sobre una norma de lectura basada en relaciones textuales (con hipotextos), de tal modo que esa norma de lectura se transforma en algoritmo textual que presupone la constitución de un género» ${ }^{21}$. De este modo, el género se convierte en un producto crítico, en el doble sentido que hemos venido viendo de poético y mimético. Por un lado, se forma en la serie de obras que «leen» sus hipotextos, continuándolos y modificándolos. Por otra parte, su formulación sólo tiene lugar en el metatexto, es decir, en el comentario que pone en claro las razones de su clasificación genérica. Metatexto que, a su vez, adquiere su genericidad de sus textos-objetos en la medida que de ellos recibe la capacidad de reescribirlos.

Ahora bien, convendría hacer algunas matizaciones a una perspectiva, paradójicamente, tan abarcadora y tan restrictiva, desde las propias posibilidades que ofrece el modelo de Genette y que el propio Schaeffer ha desbrozado. Como no puede obviarse, conferir a las relaciones hipertextuales la condición de norma de lectura genérica puede llegar a fundar una causalidad rígida. Sin duda, cada obra adopta un molde genérico que significa, más que seguir unas reglas abstractas, deducirlas de obras anteriores en cuya estela se quiere insertar. Pero esta relación no es jamás unívoca, ni siquiera en el caso de aparición de un género, que es siempre una operación de lectura (el Lazarillo inaugura la «novela picaresca» a partir del Guzmán). La capacidad de investigar los límites genéricos, necesidad cada vez más acuciante a medida que el género se va consolidando y que, al mismo tiempo, abre el camino a su extinción o transformación, exige tantear alternativas estructurales, estilísticas o temáticas que innoven, sin romper, las condiciones de identidad genérica. Como es natural, puede buscarse, así, la asimilación de rasgos de otros géneros, ya sea mediante recontextualización o descontextualización de su situación de origen ${ }^{22}$. Pero

${ }^{19}$ G. Genette, Palimpsestos, Madrid, Taurus, 1989, p. 14.

${ }^{20}$ Ibid., p. 17.

${ }^{21}$ J. M. SCHAEFFER, «Del texto al género. Notas sobre la problemática genérica», en M. Á. GARRIDO Gallardo (ed.), op. cit., p. 175.

22 Jean Marie SCHAEFFER, Qu'est-ce qu'un genre littéraire?, París, Seuil, 1989, p. 142. 
no es necesario que tal relación sea siempre hipertextual en sentido estricto, pues en ocasiones pueden aprovecharse rasgos que no caracterizan de por sí al hipotexto sino que este, en su momento, incorporó de otros géneros. De este modo, sobre un mismo rasgo es posible llevar a cabo un doble proceso de transformación que, si bien se inspira en la hipertextualidad, amplía su radio de acción a un conjunto de semejanzas que dan pie a nuevos hibridismos y que hacen que las clases genéricas «son très souvent des classes impures, et seule une analyse détaillée peut faire la part de la place respective qu'y prennent les relations de pure ressemblance et les relations hypertextuelles» ${ }^{23}$. Así ha de entenderse la ampliación que Schaeffer hace del significado de hipertextual a toda filiación plausible que pueda establecerse entre un texto y otro o un conjunto de textos anteriores o contemporáneos, sobre cuyos rasgos intratextuales o índices paratextuales sea lícito postular que han funcionado como modelos genéricos del primero, ya sea que los haya imitado, ya desviado, mezclado o invertido.

$\mathrm{Y}$, sin embargo, creo que es conveniente, como postula Genette, mantener la noción de hipertextualidad en su aspecto más definido para evitar que, a la postre, todas las obras se conviertan, sin más, en hipertextuales. Pero no sólo porque, de este modo, se conciba «la relación entre el texto y su lector de una manera más socializada, más abiertamente contractual, formando parte de una pragmática consciente y organizada» ${ }^{24}$, sino también porque entonces es posible advertir con más nitidez la impureza de las clases genéricas, basada, tal como pretende Schaeffer, en el entrecruzamiento de las relaciones de semejanza (analógicas) y las hipertextuales (genealógicas). Fijando la genealogía, se mantiene así el riguroso criterio filológico de la imitación de modelos, pero, admitiendo y acogiendo las analogías, ya sean temáticas, estilísticas o estructurales, la «imitación» recobra su dimensión propia de variatio, que está en la base de la defensa de la «imitación compuesta». Es posible aceptar así, en un primer momento, el concepto de analogía hipertextual. Todos los textos dependen unos de otros, a menudo a través de mediaciones que enriquecen la tradición. En un segundo momento, cabría hablar de una hipertextualidad analógica, pues las relaciones genealógicas sólo es posible establecerlas en el curso de la tradición y es, por tanto, un asunto de historia literaria. Desde esta perspectiva, no puedo evitar discrepar de Genette, aunque sea por una mera cuestión terminológica. Entre hipertextualidad e imitación no existe una relación de inclusividad, por más que sea colocada la imitación como la relación marcada entre las prácticas hipertextuales ${ }^{25}$. Ambas mantienen una relación dialéctica, irreductible, como dijimos, a síntesis, aunque, en un ni-

\footnotetext{
${ }^{23}$ Ibíd., pp. 173-174.

${ }^{24}$ G. GENETTE, Palimpsestos, p. 17.

${ }^{25}$ Ibíd.., p. 41.
} 
vel teórico, sea preciso reconocerle un rendimiento superior a la hipertextualidad. Sin ella, la imitación degenera en búsqueda de fuentes y de lugares temáticos y estilísticos paralelos, sin conexión con la productividad genérica del sistema literario. Ahora bien, sin la «imitación», en el sentido múltiple que las Poéticas clasicistas le concedían, la hipertextualidad carece del instrumento que da cuenta tanto de detalles retórico-gramaticales cuanto de la capacidad de asimilación de rasgos intergenéricos.

El propio Genette es consciente del complicado estatuto de la «imitación», pues debe admitir que, frente a las relaciones de transformación, la imitación «exige la constitución previa de un modelo de competencia genérica $[\ldots]$ capaz de engendrar un número indefinido de performances miméticas. Así pues, entre el texto imitado y el texto imitador, este modelo constituye una etapa y una mediación indispensable, que no se encuentra en la transformación simple o directa» ${ }^{26}$. Pero, aun en este caso, la «imitación» sigue siendo deudora de su acepción mimética, dejando a un lado la capacidad productiva de la «imitación lingüística y literaria», que pasa a convertirse en el conjunto de procedimientos que dan lugar a las diferentes prácticas hipertextuales de la imitación: pastiche, imitación satírica e imitación seria. No cabe duda de la validez teórica del marco general propuesto por Genette, cuya utilidad es incuestionable para evitar la parálisis «imitativa». Pero en ese cuadro, la noción de «imitación» sigue provocando cierto malestar, procedente de la asimilación en un paradigma estructuralista de un concepto connotadamente histórico y hasta historicista.

Las próximas páginas se acercarán al carácter ambiguo, impuro, de ese espacio donde se interseccionan hipertextualidad e imitación, de acuerdo con la propuesta inicial de llevar a cabo una poética práctica. Para ello, se seguirá el rastro de un motivo muy específico: el de los «espíritus de amor». En la poesía de Garcilaso, ejemplo supremo de clasicidad poética española a partir de los comentarios del Brocense y de las anotaciones de Herrera, se tematiza sólo en el soneto VIII ( $«$ De aquella vista pura y excelente / salen espirtus vivos y encendidos») y, en menor medida, en los tercetos del soneto XVIII ( $\ll \mathrm{Si}$ a vuestra voluntad yo soy de cera»), mientras tan sólo se perciben ecos de él en la Canción IV (vv 61, 65-67). Como dice Rafael Lapesa, el soneto VIII «interesa por ser el único reflejo que en la obra garcilasiana tiene el dolce stil nuovo» ${ }^{27}$, pero también porque, como veremos, en medio de las diversas fuentes que se citan, ninguna parece segura excepto la de El cortesano, en la traducción de Boscán de 1534.

En vista de las analogías hipertextuales que puedan recorrerse (desde

${ }^{26}$ Ibíd., p. 15.

27 Rafael LAPESA, La trayectoria poética de Garcilaso, Madrid, Alianza Editorial, 1985, p. 157 (1. a edición, Madrid, Revista de Occidente, 1948). 
los sonetos sicilianos a Dante y Petrarca), terreno movedizo para la crítica filológica, me aventuraré a establecer algunas sugerencias de hipertextualidades analógicas, que incluyen las posibilidades significativas del empleo de recursos métricos, como puede ser la elección de estrofas (sonetos, baladas y canciones). Atender a fuentes inciertas, como son las prepetrarquistas, facilita el percibir el sentido histórico que ejerce la crítica sobre sus objetos. A diferencia de la prudente y rigurosa búsqueda de fuentes, esta actitud ayuda a advertir las potencialidades significativas de los propios instrumentos filológicos. En este sentido, mi objetivo no es inmanentemente pragmático sino hermenéutico ${ }^{28}$. No obstante, trataré de justificar todos estos pasos desde el interior de la propia evolución poética de Garcilaso en el contexto de la imitación renacentista, abierta a una discusión histórica no reducida a un historicismo atento básicamente a la tradición petrarquista.

\section{LOS PARADIGMAS DE UNA IMITACIÓN Y SUS ANALOGÍAS}

Como acabo de dejar apuntado, la tarea que me propongo no es meramente explicativa, la de comentario de un texto que persiste como monumento del pasado, sino la de reconocer la condición histórica del fenómeno mismo del aparecer del texto como monumento. No niego, por tanto, el primer momento, que es imprescindible, desde un punto de vista metodológico, para poder realizar un tanteo sobre el sentido que el texto despliega ante nosotros. En el caso de las composiciones que se han elegido de Garcilaso, interesan no tanto los significados que cada poema induce cuanto la forma de constituirse tales significados. Para ello, es preciso atender a la dinámica interna que justifica la apropiación de un motivo singular, como son los «espíritus de amor», así como a la proyección que tal apropiación tiene en el mundo de los lectores. Según se ha definido recientemente, a propósito de la relación entre el intérprete y su objeto, «comprender un texto no es encontrar un sentido inerte contenido en él, sino desplegar las posibilidades de ser indicadas por el texto» ${ }^{29}$. En efecto, el stilnovismo del motivo elegido exige replantear una perspectiva determinada por la atención a las fuentes directas del petrarquismo. No debe olvidarse que este

\footnotetext{
${ }^{28}$ Para no perderse en sobreinterpretaciones, mi propuesta de lectura del motivo garcilasiano de los «espíritus» no debe perder de vista que el punto de partida se encuentra en «una vuelta a la lectura retórica del texto lírico; retórica en su sentido más puro: arte de creación de un discurso eficaz dirigido a un fin» (Á. L. LUJÁN ATIENZA, «Semántica y pragmática en el comentario de textos», Revista de Literatura 125 (2001): 8).

${ }_{29}$ Vicente BALAGUER, La interpretación de la narración. La teoría de Paul Ricoeur, Pamplona, Eunsa, 2002, p. 40. Para algunos de los puntos planteados en el apartado anterior, en especial las relaciones entre crítica literaria y hermenéutica, puede verse un sucinto resumen en op. cit., pp. 21-30; también, José Manuel CUESTA ABAD, «La crítica literaria y la hermenéutica», en Pedro AULlón DE HARO (ed.), Teoría de la crítica literaria, Madrid, Trotta, 1994, pp. 485-510.
} 
no consiste sólo en situarse directamente en la estela del aretino, sino en la discusión que suscitó el modo como Pietro Bembo planteó la «imitación» en la época en que Garcilaso componía su obra. Pero habré de empezar por los comentarios y anotaciones al soneto VIII de Garcilaso para poder alcanzar un ángulo de visión relativo a este conflicto.

Una de las más completas listas de fuentes de este soneto se debe al editor más constante de Garcilaso. Elias L. Rivers las sintetizó en su edición de $1974^{30}$. En esta lista Rivers pone de relieve el puesto central que ocupa un pasaje de El cortesano de Castiglione (Libro IV, capítulo 7), que transcribe por extenso y al que considera «que dio motivo a este soneto». Por el contrario, juzga «menos importantes» las «posibles influencias» notadas desde el Brocense y Herrera hasta los modernos editores, cuyo «número nos hace ver que era un tópico ya consagrado de la poesía amorosa el tema de los rayos "visivos" que salen de los ojos de la hermosa dama y que a través de los ojos de él hieren en el corazón al enamorado que la contempla». En último término, Rivers se inclina por una ascendencia neoplatónica que culmina en Marsilio Ficino y tiene su origen en el Fedro de Platón.

En su edición de Garcilaso, Bienvenido Morros insiste en la segura fuente de El cortesano, pues desde Lapesa se ha fechado este poema en la etapa final y no durante el primer viaje a Italia ${ }^{31}$. Si Lapesa lo fechaba en Italia en 1535, Rivers, en virtud de las coincidencias verbales con el pasaje de Castiglione, proponía el arco entre 1533 y 1535. Para Morros, que recoge la idea de que el modelo de Castiglione se remonta al Fedro, al que añade los cauces de un neoplatonismo ahora de «origen astral», «la deuda con Boscán y su perfecta construcción obligan a considerarlo de fecha tardía, con absoluta seguridad posterior a la primavera de 1533». Sin embargo, a diferencia de Rivers, concreta el tema de los «rayos visivos» en «conceptos de la medicina y filosofía antiguas, aplicadas al enamoramiento ya por los representantes del dolce stil nuovo» y cita de pasada en la nota al verso 14 a Alberto Magno por medio de Herrera ${ }^{32}$.

\footnotetext{
${ }^{30}$ GARCILASO DE LA Vega, Obras completas, edición de Elias L. Rivers, Madrid, Castalia, 1974, pp. 86-88. Previamente, había tratado ya las fuentes en el artículo «The sources of Garcilaso's sonnet VIII», Romance Notes 2 (1961): 96-100.

${ }^{31}$ R. LAPESA, op. cit., p. 192, n. 236. Discrepa Antonio Prieto, que insiste en una datación temprana del soneto, no por la novedad del contenido que reconoce que trae a la poesía española sino por el lugar que le asigna en la trayectoria de la poesía garcilasiana como «cancionero», «cuando aún un saber (el saber del elocuente) priva especialmente sobre la experiencia del sentimiento (A. PRIETO, La poesía española del siglo XVI (I. Andáis tras mis escritos), Madrid, Cátedra, pp. 88-90; para la cita, p. 89).

${ }^{32}$ GaRcilaso DE LA VEGA, Obra poética y textos en prosa, edición de Bienvenido Morros, Barcelona, Crítica, 2001, pp. 28-29 (1. ${ }^{a}$ edición, 1995). F. DE HERRERA, op. cit., pp. 334-335 (335-336). Rivers añade al De spiritu et respiratione, que cita Herrera en castellano, el «De anima, etc.» (op. cit., p. 88).
} 
Por su parte, Antonio Prieto había admitido la influencia de Castiglione, pero no la hacía remontar a Platón, sino directamente a Marsilio Ficinio, pues le interesaba resaltar la relación con la poesía de Cavalcanti, siendo la primera vez que aparecía en la crítica española la alusión concreta a un stilnovista $^{33}$. Si Bienvenido Morros, en su edición posterior, estructura la separación entre tercetos y cuartetos en función de una oposición temático-retórica (que, como veremos enseguida, puede ser entendida como un eco de la «imitación lingüística»), Prieto optaba por un cambio de fuentes que, en definitiva, respondería a una decisión de «imitación compuesta» ${ }^{34}$. La ventaja de la solución de Antonio Prieto consiste en que deja a un lado la ascendencia platónica que, en último término, llegaría a Garcilaso a través de Castiglione. La cita de Ficino proporcionada por Rivers, por otra parte, no remite a fuentes neoplatónicas sino que alude a las teorías fisiológicas de Alberto Magno. Por el contrario, la referencia de Prieto sitúa, más coherentemente, la fuente ficiniana no en la Oratio VI sino en la Oratio VII del Commentarium in Convivium Platonis o, en versión vulgar, Sopra lo amore. En ella Ficino comienza con una conclusión de todo lo dicho en su obra «con la oppenione di Guido Cavalcanti filosofo» ${ }^{35}$. Es obvio que la interpretación de Ficino es platonizante y alegórica, hasta el punto que transtorna el sensualismo cavalcantiano en «espiritualismo». Sin embargo, pone en la pista correcta si nos fijamos en las «coincidencias verbales» de la fuente de Cavalcanti en lugar de las de la fuente platónica. Fuente de Cavalcanti, la de Alberto Magno, que, paradójicamente, es desarrollada en la Oratio VI, mientras que en la Oratio VII la resolución alegórica de «sol y rayos» como «luz de Dios» y «forma del cuerpo» respectivamente es completamente neoplatónica.

Antes de seguir, y con el fin de resaltar la utilidad de este rastreo de fuentes, será preciso detenerse un instante en la hipermetría que el Brocense detectó en el v. 5 («Encuéntranse en el camino fácilmente»). Él resolvía, sin más, como «éntranse en el camino fácilmente». Alberto Blecua, con apoyos ecdóticos e intratextuales sólidos, ha venido a dar la razón al gramático y retórico salmantino ${ }^{36}$. Las ediciones posteriores (Rivers, Prieto,

${ }^{33}$ GaRCILASO DE LA VEgA, Cancionero (Poesías castellanas completas), edición de Antonio Prieto, Madrid, Bruguera, 1984, p. 137. Sobre la influencia de autores stilnovistas en la poesía de Garcilaso, vid. E. MELE, «In margine alle poesie di Garcilaso de la Vega», Bulletin Hispanique 32 (1930): 218-245; y, en especial, ORESTE FRATTONI, «Influssi prepetrarcheschi nei sonetti di Garcilaso», Italica XXV, 4 (1948): 300-305.

${ }^{34}$ Morros aplica la figura de anadiplosis y antítesis a las oposiciones temáticas que describía su «fuente», el libro de Alberto BlecuA, En el texto de Garcilaso, Madrid, Ínsula, 1970, pp. 39-40.

${ }^{35}$ Marsilio FICINo, Sopra lo amore o'ver Convito di Platone, Milano, CELUC, 1973, pp. 129-131. Insiste en la relación entre los ojos y el amor en el capítulo 10 de este Discurso VII.

${ }^{36}$ A. Blecua, op. cit., pp. 34-38. 
Morros) han aceptado la enmienda que resulta indiscutible. Por ello, no me parece el camino más fructífero atender los aspectos lexicográficos para destacar la influencia de Dante o Ausias March, por medio de una extrapolación cultural, como ha hecho la otra editora reciente de Garcilaso, Maria Rosso Gallo ${ }^{37}$. Lo que se ventila, como he dicho antes, es la preeminencia, en este caso, de una «imitación lingüística» sobre una «imitación de modelos». Mientras que si nos atenemos a la primera, es preciso obedecer a los rigurosos criterios explicativos de la crítica textual, en tanto que rama de las ciencias humanas, si indagamos en las potencialidades de la imitación literaria, habremos de asumir aquellos criterios explicativos que nos ayuden a comprender la proyección del sentido del poema como su propia dinámica individual. Por ello, la solución «éntranse» esclarece la coherencia del poema, métrica y semáticamente, sin negar, antes al contrario, una genealogía que, incluso más allá de Dante, puede remontarse a Cavalcanti y a los poetas sicilianos. Por todo ello, en mi propuesta de interpretación, la capacidad mimética nunca ha de descuidar los aspectos singulares, desde los cuales pueden inducirse las conclusiones, aunque siempre en un cuadro histórico que haga posibles las unas y las otras. En aquel viven, se mueven y existen unas y otras, porque fundan la posibilidad misma del acontecer interpretativo.

Pero, previamente a decantarnos por la presencia de prepetrarquistas, recuperemos el hilo de la influencia de Alberto Magno frente a la de Platón. En Fedro la vista es el sentido, y también la facultad, por el cual el hombre accede a la cuarta forma de locura que consiste en remontarse de la belleza de este mundo a la contemplación suprema de la Belleza en sí. La descripción de los efectos de esta «locura» - el deseo de conocer o el de sólo generar - son recogidos en la Oratio II de la obra de Ficino. Sin embargo, la metáfora empleada por Platón poco tiene que ver con la teoría fisiológica de los «espíritus». El filósofo griego emplea la metáfora de la germinación de las alas que ayudarán a subir hacia la idea de Belleza. En este contexto es donde, sin especificar, señala que el enamorado «siempre que pone su vista en la belleza del amado, al recoger de él unas partículas que vienen a ella en forma de corriente $-\mathrm{y}$ por eso precisamente se le da el nombre de «flujo de pasión»-, se reanima y calienta, se alivia de sus penas y se alegra» ${ }^{38}$. En este «flujo de pasión» se pueden adivinar algunos rasgos de la descripción fisiológica de los «espíritus» que Herrera anota y que combina con citas de Plutarco y Plotino. Con todo, es la exposición

${ }^{37}$ Maria Rosso Gallo, «"Encontrar el camino": A propósito de un verso de Garcilaso (Soneto VIII, 5)», Filología XXIII, 1 (1988): 17-28; posteriormente, en su edición La poesía de Garcilaso de la Vega. Análisis filológico y texto crítico, Madrid, Anejos del Boletín de la R.A.E., 1990, pp. 141-154.

${ }^{38}$ Platón, El banquete, Fedón, Fedro, traducción de Luis Gil, Barcelona, Labor, 1987, p. 323. 
de Alberto Magno acerca del movimiento de los «espíritus» en De spiritu et respiratione la que sirve de base a los tercetos $\mathrm{y}$, aun como sustrato, a los cuartetos. El obispo de Ratisbona distingue tres movimientos: según la naturaleza de la materia, según el alma y según la disposición del corazón. Los «espíritus», que se diferencian del alma por ser substancia corpórea, suben desde el corazón al cerebro y salen por la vista ${ }^{39}$. Facilitan así el sentir, el imaginar, el recordar y el entender que son actividades propias del alma, hasta el punto que en ocasiones se confunden los «espíritus» con la imaginativa, a la que se define como «vis animae quaedam mente inferior, in qua imagines rerum imprimuntur; sed hoc modo non sumus hic locuti de spiritu, eo quod in hoc opere non nisi physica tractare suscepimus» ${ }^{40}$. Parece evidente, pues, que Garcilaso opera sobre la fuente directa del Cortesano una revisión del marco filosófico de la teoría de Alberto Magno, en lugar de la etiología fisiopatológica que fascina a Herrera. Sobre tal marco, a su vez, Garcilaso ejerce una restricción humanista al dotar de voluntad, si bien una voluntad- «desmesurada», a los espíritus: «Ausente, en la memoria la imagino; / mis espirtus, pensando que la vían, / se mueven y se encienden sin medida». Es este punto, con la atracción de los espíritus a la imaginativa, el que permite a Herrera su disquisición acerca de la memoria en Aristóteles, aunque, en alguna manera, este desplazamiento estaba ya recogido por Alberto Magno.

Ahora bien, ¿en qué medida puede sostenerse que Garcilaso modula sus «espíritus» en este soneto bajo el modelo del stilnovismo, a través del cual le habría llegado esta teoría fisiológica? Antes de entrar en Cavalcanti, permítaseme una breve comparación con los tercetos del soneto XVIII: «Y es que yo soy de lexos inflamado / de vuestra ardiente vista y encendido / tanto que en mi vida me sostengo apenas; // mas si de cerca soy acometido / de vuestros ojos, luego siento helado / cuajárseme la sangre por las venas». Para Lapesa es un soneto de fecha incierta (p. 193), opinión que sigue Morros. En tanto que convierte la poesía de Garcilaso en un Cancionero que hace de la vida la escritura de una trayectoria personal por el poder acrónico de la palabra, Prieto lo sitúa al comienzo de su andadura amorosa. En cualquier caso, no es baladí ni la localización ni la fecha, pues situar este soneto como anterior, o incluso como simultáneo — nunca como

${ }^{39}$ El proceso es descrito con exactitud en el primer cuarteto del soneto paródico de Lope de Vega en las Rimas del Licenciado Tomé de Burguillos, titulado «Dice cómo se engendra amor, hablando como filósofo»: «Espíritus sanguíneos vaporosos / suben del corazón a la cabeza, / y saliendo a los ojos su pureza / pasan a los que miran amorosos» (LOPE DE VEGA, Rimas humanas y otros versos, edición y estudio preliminar de Antonio Carreño, Barcelona, Crítica, 1998, p. 790).

${ }_{40}$ «Liber de spiritu et respiratione II», in Beati Alberti Magni... Parva Naturalia, recognita per R.A.P.F. Petrum Iammy, Operum Tomus Quintus, Lugduni, 1651, pp. 139159; la cita en p. 158. 
posterior - al VIII permite repensar la evolución de Garcilaso desde el petrarquismo hacia una recepción madura del magisterio provenzal. En el soneto XVIII, aparece la vista, que, como veremos, es básica en el sintagma prepetrarquista, pero la presencia de los «espíritus» es deducible sólo como sustrato cultural mestizo en un nivel profundo. Como indica Morros, «el alma inflamada por la mirada de una mujer es uno de los motivos favoritos de la lírica amorosa desde los poetas griegos», y concluye, justificadamente, que «Garcilaso se atiene fundamentalmente a Petrarca». Sólo me gustaría añadir que el «acometimiento de los ojos» que «hiela la sangre de las venas» se inclina, en este caso, más hacia la estela del Fedro que de la stilnovista, pues en Platón, antes de producirse un «flujo de pasión», «el que acaba de ser iniciado, cuando divisa un rostro divino que es una buena imitación de la Belleza, o bien la hermosura de un cuerpo, siente en primer lugar un escalofrío, y es invadido por uno de sus espantos de antaño» $\left(251^{\mathrm{a}}\right)$. En cualquier caso, es evidente que la temática del soneto XVIII y la del VIII, por más que compartan rasgos comunes, representan dos momentos de una dialéctica poética, que, aceptando que no sea narrativa, debería admitirse que puede ser no sólo artística sino hasta genérica. Máxime si tenemos en cuenta la alusión de la canción IV (vv. 61-69), que, inserta en un contexto declaradamente petrarquista y cancioneril, deudora en especial de Ausias March, puede ser puesta en relación tanto con el mundo del soneto XVIII como con el del VIII: «[los ojos] en volviéndose a mí la vez primera / con el calor del rayo que salía / de su vista, qu'en mí se difundía; / y de mis ojos la abundante vena / de lágrimas al sol que me inflamaba». Lapesa no duda en fechar esta canción entre 1529 y 1532 , es decir, anterior a las otras dos, o, como mínimo, con toda seguridad, al soneto VIII ${ }^{41}$.

Conviene deducir de este estado de cosas inicial que no es posible descartar una influencia stilnovista «directa», si bien el término «directo» no tenga que ser comprendido en el sentido filológico de «imitación» sino en el de «hipertextualidad». Si sólo fuese aceptable el primer sentido, la imitación recaería, por otra vía, en su reducción lingüística, al separar el sistema de la lengua del sistema del discurso. Es así que la relación de Garcilaso con Cavalcanti estaría basada tan sólo en la imitación «posible» de palabras dentro de un sistema de oposiciones poéticas, que bien pudiera ser puesto en cuarentena por el recurso a la mediación de la poesía cancioneril. En este sentido, un análisis modélico de la influencia de Cavalcanti en el soneto VIII, como el que lleva a cabo Oreste Frattoni, se

${ }^{41}$ R. LAPESA, op. cit., pp. 77-81. Morros conecta estos versos de la Canción IV con el soneto VIII (op. cit., p. 85), mientras que Prieto considera el verso segundo del soneto XVIII («y por sol tengo sólo a vuestra vista») un anticipo de los versos de la Canción IV (op. cit., p. 8). El Brocense se limita a destacar las fuentes de Bembo y Petrarca (A. GAllego MORELl, op. cit., p. 273) 
ve obligado a partir de que «cosí sarà difficile stabilire, spesso, se la lettura di Garcilaso fu diretta, ma è certo che non si puó non porre il problema» ${ }^{42}$. En efecto, no se puede no plantear el problema, porque incluso no sólo desde el plano del discurso sino también desde el plano literario del discurso histórico las polémicas sobre la imitación y el petrarquismo bembiano que Garcilaso siguió marcan el camino de la propia práctica poética del toledano. Francisco J. Ávila ha descrito claramente el proceso de formación de Garcilaso, oscilando entre Bembo y Castiglione, con el fin de sentar las bases de su lengua poética. Apoyándose en Trissino, podía aprovechar su percepción de la literatura italiana «como un mosaico atemporal», con el mismo fin de experimentar que el tratadista italiano, aunque tal punto de partida fuese inaceptable para Bembo dentro de su visión evolutiva de la literatura. El «provenzalismo» con su renovación prepetrarquista permitiría a Garcilaso contar no sólo con «el "primado del presente", sino también [con] la "imitación relativizada" propugnada por Castiglione, y no la estrictamente petrarquista de Bembo» ${ }^{43}$.

Otra vez, Castiglione y el petrarquismo bembiano reaparecen, ahora en una tensión renacentista que permite ver al primero no como una fuente opuesta a la stilnovista sino, al contrario, como un estímulo para la síntesis de un poeta cortesano. Una síntesis que no puede limitarse a ser temática o frástica sino que ha de alzarse al discurso como lugar privilegiado de la escritura poética. Por ello, sentados los cimientos de estas «analogías hipertextuales», inspiradas en la imitación de modelos, cabe arriesgarse a dar un paso más a fin de comprobar si están inscritas en un sistema hipertextual que no puede dejar de lado las implicaciones genéricas que aquellas pueden suscitar. Por cuestión de método, me limitaré a analizar las transformaciones que tengan lugar dentro de la «lírica».

${ }^{42}$ O. Frattoni, art. cit., p. 302. Cita hasta siete sonetos y cuatro canciones de Cavalcanti donde pueden encontrarse lugares paralelos al de Garcilaso (p. 304). Sin embargo, Lapesa considera que la triple herencia cristiana, clásico-latina y trovadoresca «constituye una base general que permite encontrar fáciles semejanzas entre una literatura y otras; pero si estos paralelos demuestran el parentesco histórico, no prueban que uno de los términos comparados proceda necesariamente del otro» («Poesía de cancionero y poesía italianizante», en De la Edad Media a nuestros días, Madrid, Gredos, 1971, p. 147).

${ }^{43}$ Francisco J. Ávila, El texto de Garcilaso: contexto literario, métrica y poética, Ann Arbor UMI, 2001, pp. 538 y 706. Ávila señala que la tradición provenzal no necesariamente pasaba por Italia, pues España contaba con la tradición de los Cancioneros del siglo XV y con la figura de Ausias March (p. 706). Para nuestra hipótesis, que la línea de remontada sea española o italiana, o mejor aún, una «imitación compuesta de ambas», que habría de ser estudiada, no excluye la presencia de Cavalcanti y de otros poetas, «mediados» por una tradición que, desde una perspectiva humanista, no queda reducida a una «interposición». 


\section{EL SONETO Y LA CANCIÓN EN DIÁlOGO MÉTRICO}

La organización y distribución de la poesía de Garcilaso ha obedecido, desde la edición princeps, a criterios formalizadores que se arraigaban en los criterios de imitación. A los géneros petrarquistas (sonetos y canciones) le seguían los géneros clásicos (oda, elegías, epístolas y églogas). Ya desde las Anotaciones, sin embargo, tal oposición era revisada, al filiar la canción petrarquista con la oda antigua y considerar el soneto como heredero del epigrama y de otros géneros latinos y griegos. Herrera pretendía, así, «establecer una noble y rancia tradición para la poesía en vulgar, asegurando, en definitiva, una garantía "humanística" a la existencia de cada género poético comentado» ${ }^{44}$. De este modo, la poesía lírica renacentista resultaba de la fusión de lo clásico con lo petrarquista, según el modo de la literatura latina que, a diferencia de la griega, «no empezó como transcripción de tradiciones orales y vernáculas, sino como imitación de una escritura ya existente» ${ }^{45}$.

Al modo de Horacio, esta conciencia de imitación textual de modelos puede llegar, mutatis mutandis, a recibir una distribución «figurativa» — «ut pictura poesis»— de la poesía castellana de Garcilaso en forma de «cancionero», como propone Antonio Prieto. Garcilaso se insertaría así en una tradición que, por un proceso inverso al de Herrera, bascularía hacia la tradición que se inicia en la poesía provenzal y que se bifurca y hermana en la poesía italiana y en la de cancionero español, pues «la práctica cancioneril hispánica responde a las convenciones amorosas, a los artificios métricos, a los juegos de palabras y antítesis que la poesía siciliana traslada a la toscana tras la batalla de Benevento. Con la importante distinción de que en la corte de Sicilia, los poetas ya cultivaron «naturalmente» el endecasílabo y de que un notario imperial, Jacopo da Lentini, inventó el soneto» ${ }^{46}$. En Garcilaso podría observarse así un esfuerzo por integrar ambas líneas en una lectura española de la imitación italiana ${ }^{47}$. Tal perspectiva, no obstante, privilegiaría la secuencia narrativa por encima de una más moderna conciencia de los géneros poéticos, tal como aparece en la ordenación que Boscán realiza, «siguiendo el esquema practicado por Bernardo Tasso» ${ }^{48}$.

${ }^{44}$ B. LÓPEZ BUENO, art. cit., p. 187.

${ }^{45}$ Elias L. RIVERS, «El problema de los géneros neoclásicos y la poesía de Garcilaso», en V. García de la Concha (ed.), op. cit., p. 52.

46 A. PRIETO, op. cit., p. VIII.

${ }^{47}$ Francisco Rico ha mostrado cómo los poetas de cancionero eran capaces de deconstruir motivos petrarquescos que, posteriormente, Garcilaso retomaba sintetizándolos («De Garcilaso y otros petrarquismos», Revue de Littérature Comparée (1978): 325-338).

${ }^{48}$ B. Morros, ed. cit., p. 310. 
Aunque esta distribución alterna sigue sin dar respuesta a un posible orden interno de cada uno de los géneros, al menos en el caso de Garcilaso, las conexiones entre estrofa y género resultan fundamentales para intentar dar cuenta de la trayectoria histórica de una práctica poética. Visto el paradigma métrico como un elemento esencial en la constitución del texto, funciona como «un modelo privilegiado en cuanto que ordena y fija con mucha mayor precisión que cualquier otro la relación entre constantes semántico-semióticas, de un lado, y retóricas, de otro» ${ }^{49}$. En el soneto VIII de Garcilaso, como intentaré poner de relieve, puede observarse bajo la forma métrica petrarquista un conjunto de ecos, métricos y temáticos en estrecha vinculación, que dan espesor histórico y literario a esta composición de «perfecta construcción». En primer lugar, habrá de seguirse el motivo de los «espíritus» en la Canción I de la Vita nuova de Dante y en algunas baladas de Cavalcanti para, en un segundo momento, advertir que tal motivo está también presente, no sólo en un soneto cavalcantiano, sino en la invención misma del soneto, a cargo del siciliano Giacomo da Lentini. En este trasvase métrico-temático se producen toda una serie de variaciones, que hacen de la imitación una síntesis de las posibilidades retóricosemánticas de los géneros que han acogido tal motivo, para desplegarlo en un mundo del texto que, en tanto que referencia metafórica, es el poeta Garcilaso quien primero lo actualiza como lector. Con el fin de no sobrecargar la exposición, no me detendré en delinear la formación y constitución del soneto ${ }^{50}$.

Como decía, se ha considerado fuente evidente del soneto de Garcilaso los versos 51-54 de la Canzone I de la Vita Nuova («De li occhi suoi, come ch'ella li mova, / escono spirti d'amore inflammati, / che feron li occhi a

${ }^{49}$ B. LóPEZ BUENO, «La implicación género-estrofa en el sistema poético del siglo XVI», Edad de Oro XI (1992): 103. López Bueno se inspira en la tesis de Alberto Blecua, para quien la forma en la lírica del siglo XVI está sujeta a una poética, basada en la teoría de los estilos y en la imitación de modelos, de modo que «cada estrofa tiene su peculiar función y su lugar propio» («Fernando de Herrera y la poesía de su época», en Francisco LóPEZ ESTRADA (coord.), Historia y Crítica de la Literatura Española II. Siglos de Oro: Renacimiento, Barcelona, Crítica, 1980, p. 431).

${ }^{50}$ Señalo solamente algunas entradas que habré de utilizar en relación con el origen del soneto y su evolución hasta Petrarca: Ernest HATCH WILKINS, «The Invention of the Sonnet», en The Invention of the Sonnet and other studies in Italian Literature, Roma, Edizioni di Storia e Letteratura, 1959, pp. 11-39; Elias L. RIVERS, «Certain formal characteristics of the primitive sonnet», Speculum 33 (1958): 42-55; Leo SPITZER, «Una questione di punteggiatura in un sonetto di Giacomo da Lentini (e un piccolo contributo alla storia del sonetto)», Cultura Neolatina XVIII (1958): 61-70; Aldo MENICHETTI, «Implicazioni retoriche nell'invenzione del sonetto», Strumenti critici 9 (1975): 1-30; Marco SAntagata, Dal sonetto al canzoniere, Padova, Liviana Editrice, 1979; R. ANTONELLI, «L'invenzione del sonetto», Miscellanea di studi in onore de Aurelio Roncaglia, Modena, Mucchi, 1989, pp. 35-75; W. PöTTERS, Nascita del sonetto. Metro e matemática al tempo di Federico II, Ravena, Longo, 1998. 
qual che allor la guati, / e passan sí che ' 1 cor ciascun retrova») ${ }^{51}$. El proceso descrito en el soneto coincide con el expuesto en estos versos, pero ahora me interesa retener la estructura métrica de la canzone dantesca. Se ha destacado que en el origen del soneto se encuentra la «estancia» de la canzone provenzal, si bien no tanto entendida como una forma métrica de la cual derivaría el soneto, «ma dei patterns metrici e retorici che ne hanno favorito e "modellato" l'invenzione», «appunto come struttura di riferimento, modello variabile a piacere e non come matrice» ${ }^{52}$. En el caso de Dante, casi podría hablarse de que esta operación sufre ahora un proceso de vuelta, pues, siendo esta la primera canción, tras numerosos sonetos, acepta para cada estancia el número de versos de un soneto (catorce) y, aunque el esquema métrico difiere del que tiene aquel, mantiene ciertos parecidos, como el uso de endecasílabos y una tendencia, que desarrollará el soneto elisabetiano, a culminar cada estancia con un dístico epigramático. Incluso el envío respeta, al modo de la cobla provenzal, el número de versos de las estrofas anteriores. Excepto en la segunda estancia, donde se rompe, con enorme elegancia, el equilibrio métrico-sintáctico en la diesis («Sola Pietà nostra parte difende, // che parla Dio, che di madonna intende»), las demás lo conservan. La primera, la tercera y la quinta traban la fronte y la sirma mediante un procedimiento inusual en la Vita nuova, como es el empleo de conectivos (en este caso, el más sencillo: la conjunción copulativa «e»), al estilo de los sicilianos ${ }^{53}$. La cuarta introduce el motivo de los «spirti inflammati».

Conviene no pasar por alto que en De vulgare eloquentia II, III Dante había establecido una gradación, en cuanto a la nobleza de las composiciones en lengua vulgar, desde el soneto hasta la canción, entre las que ejercía de balanza la balada ${ }^{54}$. Pues bien, al margen de la canción «Donna mi prega», detengámonos brevemente en dos baladas de Cavalcanti en donde los «spirti» son tematizados en medio de concretas decisiones léxicas y métricas. En la balada «Gli occhi di quella gentil foresetta», la primera estancia introduce nuestro motivo: «Ella mi fere sì, quando la sguardo, / ch'i' sento lo sospir tremar nel core: / esce degli occhi suoi, / che me [...] ardo, / un gentiletto spirito d'amore, lo qual é pieno di tanto valore, / quando mi giunge, l'anima va via, / come colei che soffrir nol poria» ${ }^{55}$. La balada

${ }^{51}$ M. Rosso Gallo, art. cit.: 22. Incluyo en el apéndice final esta Canción, así como el soneto lentiniano.

${ }^{52}$ M. Santagata, op. cit., p. 69.

${ }^{53}$ Ibíd.., p. 106. Para la Vita nuova, sigo la edición de Andrea Battistini, Roma, Salerno Editrice, 1995, pp. 72-83.

${ }^{54}$ Dante AlighiERI, De Vulgari Eloquentia, edición, introducción, traducción y notas de Manuel Gil Esteve y Matilde Rovira Soler, Madrid, Palas Atenea, 1997, pp. 174-179.

55 Guido Cavalcanti, Cancionero, edición de Juan Ramón Masoliver, Madrid, Siruela, 1990, p. 70. 
no tiene el significado preciso de una estrofa de diez versos endecasílabos, dispuestos en tres partes semejantes al villancico, con su enlace y su vuelta ${ }^{56}$. Se trata más bien de una canción italiana semejante al villancico. En esta balada, una letra de tres versos es seguida por cuatro estancias de siete versos endecasílabos, con dos mudanzas, un verso de enlace y un pareado final que, sin ser estribillo, rima con la letra inicial. El envío mantiene el mismo número de versos que las anteriores estancias.

En la siguiente balada se insiste en un aspecto dual, inexistente en Dante, que porta consigo el espíritu de amor: la vida que es muerte. Formada por tres estancias de diez versos endecasílabos y heptasílabos, con mudanzas de tres versos (AbC, AbC), en lugar de dos, seguidas por un verso de enlace, un pareado suelto, y un verso final que rima con la cabeza, esta balada no concluye con un envío. La libertad de la composición se sostiene en la autonomía, métrica que no rompe con la tradición sino que la reinterpreta dentro de sus propios límites. El esquema del villancico no desaparece sino que se esconde bajo la pulsión del movimiento amoroso que necesita del diálogo hasta consigo mismo para salir de la afasia contemplativa, como muestra la letra inicial:. «Quando di morte mi conven trar vita / e di pesanza gioia, / come di tanta noia / lo spirito d'amor d'amar m'invita?» (p. 74).

En cambio, el soneto cavalcantiano más próximo a la exposición de los «espíritus», apenas tiene más contacto con el garcilasiano que la alusión a la vista («Voi che per li occhi mi passaste 'l core») y a los espíritus. ¿Cuál es entonces esa relación métrica-temática directa del soneto garcilasiano con la poesía prepetrarquista? Creo que es preciso acudir a Giacomo da Lentini para observar cómo, bajo el modelo del soneto petrarquista, Garcilaso logra la perfección formal, y estética, integrando los moldes originales en una imitación que recubre diversas capas culturales. Detengámonos en el soneto del Notario que completa la famosa tensó con Jacopo Mostacci y Pier de la Vigna. En él se trata de cómo el amor nace de los ojos, los cuales se convierten en el motivo central del poema: «da la vista de li occhi ha nas[ci]mento: / ché li occhi rappresenta[n] a lo core» ${ }^{57}$. Siguiendo una característica acusada de los sonetos sicilianos, por su genealogía con la canción según Santagata, entre el último verso del segundo cuarteto y el primer verso del primer terceto, se produce una repetición léxica que contribuye a la particular fisiognomía del soneto lentiniano ${ }^{58}$. Junto a ello,

\footnotetext{
${ }^{56}$ José Domínguez CaPARrós, Manual de métrica española, Madrid, Alianza Editorial, 1998 , p. 52.

57 Poeti del Duecento I, a cura di Gianfranco Contini, Milano, Ricardo Ricciardi Editore, 1960, p. 90.

${ }^{58}$ En bastantes casos tiene lugar «una particolare categoría di ripetizioni caratterizzata dal fatto che gli elementi lessicali si associano a ripetizioni foniche no prive, spesso, di rilevanza métrica» (M. SANTAGATA, op. cit., p. 71).
} 
desde un punto de vista temático, más importante resulta que en el proceso visual que engendra el amor los tercetos describen que el corazón concibe e imagina el deseo representado por los ojos.

Fijémonos ahora en el soneto de Garcilaso. La oposición presencia / ausencia, propia de los cancioneros, sucede en el tránsito entre los cuartetos y los tercetos, mediante una suavísima rima interna: «llamados d'aquel bien qu'stá presente. // Ausente, en la memoria la imagino». El aristotelismo que Herrera comenta en este verso, así como, al mismo tiempo, la interpretación neoplatónica que puede hacerse de él a través de la fuente de $E l$ cortesano, bien podría venir igualmente de la posibilidad concedida por Alberto Magno que fue señalada en su momento. Sin embargo, todas esas posibilidades pueden estar dadas, y unificadas, por la reinterpretación que los poetas italianos desde el Notario Lentini habían acuñado a partir del motivo de los espíritus ${ }^{59}$. Téngase en cuenta además que en Garcilaso esta oposición se produce en un presente único, cuyo desplazamiento lógico se advierte sólo por el pretérito imperfecto de las oraciones subordinadas («pensando que la vían», «que los suyos entrando derretían»). Garcilaso actualiza en su ucronía poética algo latente en los sonetos de da Lentini que, según Spitzer, «sono statatici (formulati nel presente), come segue dalla loro natura di descrizione ontologica dell'amore. Ma in qualcheduno si mostra una tendenza a racchiudere..una considerazione del passato, o speranze, che evocano un futuro» ${ }^{60}$. En el soneto de Garcilaso ese movimiento, enseñado en su modernidad por Dante y después por Petrarca, se resuelve en desesperación («revientan por salir do no hay salida»). Ahora bien, Garcilaso logra desde la tradición potenciar el motivo más allá de una imitación petrarquista que se debilita métricamente, por ejemplo, en los sonetos que Boscán le dedica a los espíritus, donde el juego temporal se basa en el uso inelegante del futuro a través de las interrogaciones retóricas que abren los sonetos y el empleo torpe de conectores, como «luego», en lugar de una trabazón lógica y sintáctica entre cuartetos y tercetos que Garcilaso consigue en sus mejores poemas sin romper la fluidez lingüística que el magisterio de Petrarca había legado ${ }^{61}$.

En un sentido, por otra parte, propio de las clases analógicas, cuya definición se apoya estadísticamente, según Schaeffer, lo que convierte, por

\footnotetext{
${ }^{59}$ Esos «espíritus» que representan la imagen amada proporcionan a Giacomo y a sus compañeros la oportunidad «di impadronirsi con una sorta di fattura verbale dell'oggetto amato e di installarlo nella loro interiorità come una pittura di devozione» (Rolando DAMIÁN, «La dama del cuore in Giacomo da Lentini», en La poesia di Giacomo da Lentini. Scienza e Filosofia nel XIII secolo in Sicilia e nel Mediterráneo Occidentale, a cura di Rossend Arqués, Palermo, 2000, p. 209).

${ }^{60}$ L. SPITZER, art. cit.: 69.

${ }^{61} \mathrm{Me}$ refiero a los sonetos «¿Cuándo será que buelva a ver los ojos....» y, sobre todo, «¿Quién me dará un coraçón tan alto...» (Juan BosCÁN, Obras, edición, estudio y notas de Carlos Clavería, Barcelona, PPU, 1991, pp. 252 y 293).
} 
tanto, su genericidad en puramente lectorial, cabría destacar en Garcilaso que, así como la homogeneidad es total en el esquema métrico de los cuartetos, diverso del esquema de los sicilianos (una octava formada por endecasílabos con rima alterna: $\mathrm{ABABABAB}$ ), en el caso de los tercetos encontramos que el $85 \%$ presenta tres rimas. Por otra parte, en Boscán los tercetos encadenados y con doble rima (CDCCDC) tienen una presencia mayor. Además, dieciocho de los sonetos de Garcilaso (45\%) reproducen el esquema habitual de los tercetos sicilianos (CDECDE). Obviamente, esto no quiere sugerir que Garcilaso se inspirase directamente en ellos, sino que su propia práctica poética le impulsaba a un dinamismo inherente entre imitatio y variatio.

En el tránsito de la (pura) analogía hipertextual a la hipertextualidad (puramente) analógica, el soneto VIII de Garcilaso, pues, no sólo asume un motivo, como ocurre en los versos de la Canción IV, sino que lleva un paso más allá la comprensión petrarquista del soneto XVIII ${ }^{62}$. El poeta cortesano logra la originalidad superior en una imitación capaz de fundir y transformar, en la plena armonía renacentista, las potencialidades poligenéricas del soneto ${ }^{63}$.

\title{
4. APÉNDICES
}

a) Soneto de Giacomo da Lentini en la tensó con Jacopo Mostacci y Pier della Vigna.

\author{
Amor è un[o] desio che ven da core \\ per abondanza di gran piacimento, \\ e li occhi in prima genera[n] l'amore \\ e lo core li dà nutricamento. \\ Ben è alcuna fiata om amatore \\ senza vedere so "namoramento, \\ ma quell'amor che stringe con furore \\ da la vista di li occhi ha nas[ci]mento: \\ ché li occhi rappresenta[n] a lo core \\ d'onni cosa che veden bono e rio, \\ com'è formata natural[e]mente; \\ e lo cor, che di zo è concipitore, \\ imagina, e li piace quel desio: \\ e questo amore regna fra la zente.
}

\footnotetext{
${ }^{62}$ F. DE HERRERA, op. cit., pp. 404-406 (pp. 363-364).

${ }^{63}$ Para Aldo Menichetti, los sonetos lentinianos, como síntesis de los sicilianos en su conjunto, se caracterizan por una tensión recíproca de dos dinamismos contrastantes, «quello centrífugo, che sfrutta ed acentúa la potenzialità insita nella bipartizione metrica, e quello centripeto, che invece tende a sottolineare e ricomporre l'unitarietà primaria della forma» (art. cit.: 25).
} 
b) Canción I de la Vita Nuova de Dante.

Donne ch'avete intelletto d'amore i' vo' con voi de la mia donna dire, non perch'io creda sua laude finire, ma ragionar per isfogar la mente. Io dico che pensando il suo valore, Amor sí dolce mi si fa sentire, che s'io allora non perdessi ardire, farei parlando innamorar la gente. E io non vo' parlar sí altamente, ch'io divenisse per temenza vile; ma tratterò del suo stato gentile a rispetto di lei leggeramente, donne e donzelle amorose, con vui, ché non è cosa da parlarne altrui.

Angelo clama in divino intelletto e dice: «Sire, nel mondo si vede meraviglia ne l'atto che procede d'un'anima che "nfin qua su risplende». Lo cielo, che non have altro difetto che d'aver lei, al suo segnor la chiede, e ciascun santo ne grida merzede. Sola Pietà nostra parte difende, che parla Dio, che di madonna intende: «Diletti miei, or sofferite in pace che vostra spene sia quanto me piace lá 'v'è alcun che perder lei s'attende, e che dirà ne lo inferno: $\mathrm{O}$ mal nati, io vidi la speranza de' beati»

Madonna è disiata in sommo cielo: or voi di sua virtú farvi savere. Dico, qual vuol gentil donna parere vada con lei, che quando va per via, gitta nei cor villani Amore un gelo, per che onne lor pensero agghiaccia e pere; e qual sofrisse di starla a vedere diverria nobil cosa, o si morria.

E quando trova alcun che degno sia di veder lei, quei prova sua vertute, ché li avvien, ciò che li dona, in salute, e sí l'umilia, ch'ogni offesa oblia. Ancor l'ha Dio per maggior grazia dato che non pò mal finir chi l'ha parlato.

Dice di lei Amor: «Cosa mortale come esser pò sí adorna e sí pura?». Poi la reguarda, e fra se stesso giura che Dio 'ntenda di far cosa nova. 
Color di perle ha quasi, in forma quale convene a donna aver, non for misura: ella è quanto de ben pò far natura; per essemplo di lei bieltá si prova. De li occhi suoi, come ch'ella li mova, escono spirti d'amore inflammati, che feron li occhi a qual che allor la guati, e passan sí che 'l cor ciascun retrova: voi le vedete Amor pinto nel viso, là 've non pote alcun mirarla fiso.

Canzone, io so che tu girai parlando a donne assai, quand'io t'avrò avanzata. Or t'ammonisco, perch'io t'ho allevata per figliuola d'Amor giovane e piana, che là 've giugni tu diche pregando: «Insegnatemi gir, ch'io son mandata a quella di cui laude so' adornata». E se non vuoli andar sí come vana, non restare ove sia gente villana: ingegnati, se puoi, d'esser palese solo con donne o con omo cortese, che ti merranno là per via tostana.

Tu troverai Amor con esso lei ;

Raccomandami a lui come tu dei. 


\title{
RESUMEN
}

\section{Hipertextualidad e imitación (A propósito de los «espíritus de amor» en Garcilaso), por Armando Pego Puigbó.}

La noción de «hipertextualidad» literaria, acuñada por Gerard Genette en su libro Palimpsestes, forma parte de los conceptos teóricos que han caracterizado el paradigma de la teoría literaria postestructuralista. Por su parte, la teoría de la «imitación» constituye el fundamento indiscutible de la poética renacentista. En el presente artículo se destacan los entrecruzamientos entre un concepto y otro, así como se pone de relieve su utilidad a la hora de interpretar nuestros textos clásicos. Como ejemplo, se ha elegido aquí el soneto VIII de Garcilaso. A través de una rápida descripción de los comentarios que ha suscitado el famoso motivo de los «espirtus vivos y encendidos» (v. 2), puede observarse que la comprensión del poema se enriquece no sólo con la localización de fuentes y de préstamos lingüísticos sino también con el descubrimiento de las relaciones métricas y genéricas entre el hipertexto y sus (posibles) hipotextos. En el caso del soneto garcilasiano, gracias a la fijación de sus fuentes temáticas, es posible proponer un hilo que hace remontar las semejanzas genéricas desde la Canción «Donna ch'avete» de Dante hasta los sonetos sicilianos de Giacomo da Lentini. El estudio de las fuentes prepetrarquistas contribuye a matizar la poética renacentista desde una perspectiva transtextual pero también hermenéutica.

Palabras clave: Renacimiento, Garcilaso, Soneto, Imitación, Hipertextualidad.

\begin{abstract}
The concept of literary «hypertextuality», which was coined by Gerard Genette in Palimpsestes, has characterized an important area of the post-estructuralistic paradigm. On the other hand, the theory of «imitation» represents the basis of the Renaissance poetics. In this article the relations between both concepts are tried to be highlighted. At the same time, their validity for interpreting the classical texts is tested. As an example, the Garcilaso's sonnet VIII has been chosen. Through a brief description of the commentaries about a famous lyrical motive - that of the «espirtus vivos y encendidos»-, the understanding of the sonnet is seen to be enriched not only with the catalogue of its sources and linguistic exchanges but also with the discovery of the metric and generic links between a hypertext and its (possible) hypotexts. After discussing Garcilaso's thematic sources, it is possible for his poem to be located in a tradition which goes back, beyond the Dante's Canzone «Donna ch'avete», to the sicilian sonnets in the thirteenth century. The study of the prepetrarchist sources might help to improve our understanding of the Spanish Renaissance Literature from a transtextual and hermeneutic point of view.
\end{abstract}

Key Words: Renaissance, Garcilaso, Sonnet, Imitation, Hypertextuality. 